\title{
Ecological Diversity and Abundance of Earthworms in Sylhet Metropolitan Area of Bangladesh
}

\author{
Athar Ali Makin, Md. Faruque Miah", Satish Kumar Yadav, Mitu Deb, Zobada Kanak Khan \\ Department of Genetic Engineering and Biotechnology, Shahjalal University of Science and Technology, Sylhet, Bangladesh \\ *Corresponding Author: faruque-btc@sust.edu
}

Copyright $@ 2014$ Horizon Research Publishing All rights reserved.

\begin{abstract}
In this study, ecological diversity and species richness of earthworms were examined in different habitats of Sylhet Metropolitan area of Bangladesh. A total of eight earthworm species such as Eisenia fetida, Amynthus aspergillum, Aporrectodea caliginosa, Aporrectodea longa, Lumbricus castaneus, Lumbricus terrestris, Lumbricus rubellus and Octolasion cyaneum were morphologically identified from this study. The diversity and distribution of earthworm species related to species abundance was also investigated. Highest earthworm abundance was recorded in Kazitula while it was the minimal in case of Baluchor locality. The species E. fetida dominated in all the habitats. The relative density and species diversity index showed the species inhabiting particular habitat. The entire observation clearly indicated that the richness of earthworm biodiversity in that study location was high.
\end{abstract}

Keywords Earthworms, Biodiversity, Abundance, Ecology, Sylhet, Bangladesh

\section{Introduction}

Earthworms though well studied organisms all over the world are badly neglected in Bangladesh. Even the work on their taxonomy is far beyond completion [1]. It has been stated that more than 3000 species of earthworms are known but no taxonomic record was found in Bangladesh. Earthworms are hermaphrodites and they can double their population in one month in ideal conditions of temperature, moisture and food, which is organic matter [2]. Earthworms are an important organism in the soil doing great service for mankind for millions of years now. It combines immense social, economic and environmental values together which is now being realized and recognized. A newer branch of biotechnology called 'Vermiculture Technology' is emerging by the use of earthworms to solve various environmental problems from waste management to land (soil) improvement. Earthworms when present in soil inevitably work as 'soil conditioner' to improve its physical, chemical and biological properties and also its nutritive value for healthy plant growth. Increased activities potentially favors increase in aeration, aggregate stability, water infiltration, mixing and decomposition of plants residue, availability of organic and inorganic nutrients, which directly or indirectly enhances the productivity of soil. Earthworms play a versatile role in soil biology and fertility. Earthworms secrete enzymes, proteases, lipases, amylases, cellulases and chitinases which bring about rapid biochemical conversion of the cellulosic and the proteinaceous materials in the variety of organic wastes which originate from homes, gardens, dairies and farms [3]. They are found in all types of soils but their density and diversity of earthworms are mainly controlled by environmental factors that influence their biological cycles, such as temperature, moisture, organic carbon supply. Belonging to class Oligochaeta, earthworms form the major terrestrial and soil inhabiting organisms of Phylum Annelida. Most of the species of earthworm can be divided into three broad groups, such as Epigeic (litter dwelling) species (Lumbricus rubellus), Endogeic (soil dwelling) species (Aporrectodea spp.) and Anecic (deep burrowing) species (lumbricus terrestris) [4-6].

Earthworm population dynamics in relation to different soil types has influence of vegetation on population dynamics of earthworm $[7,8]$ but it was not well been studied in Bangladesh. Though Ghosh presented the ecological aspects of Bangladeshi earthworms along with their vermicomposting technique [4] but there is no other scientific report on the effect of agricultural practices on the earthworm population in Bangladesh, a country whose economy is based on agriculture [9]. In addition, no report on distribution and abundance of earthworms are available in Bangladesh. Therefore, the present study was carried out to determine the actual condition of the earthworm biodiversity in the Sylhet Metropolitan area along with its soil characteristics. This information is very essential to take necessary steps to study and work with earthworm which has impact in environment. 


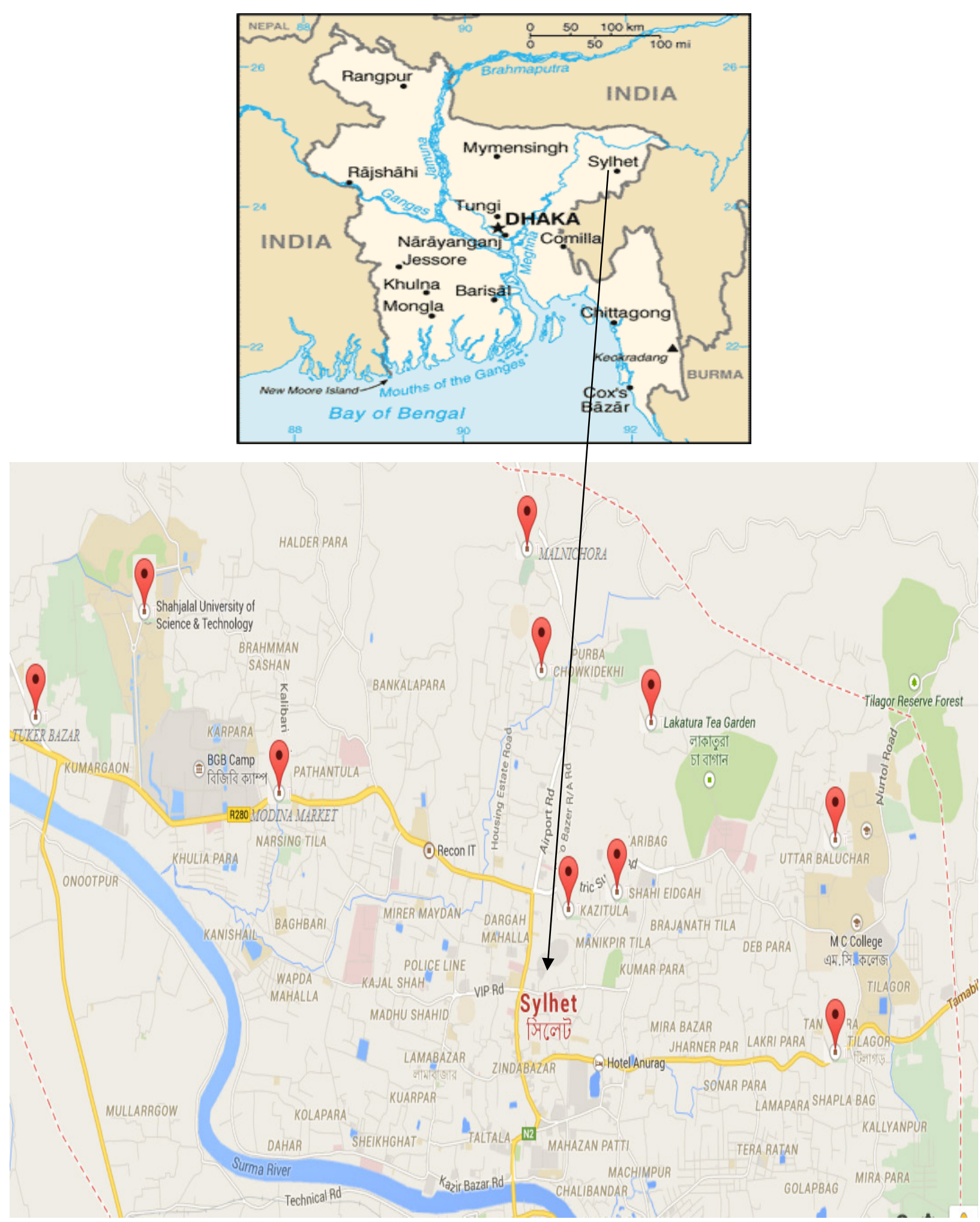

Figure 1. Locations of study sites 


\section{Materials and Methods}

\subsection{Study Site}

The survey and collection was conducted during post monsoon from October 2013 to December 2013 in Sylhet Metropolitan area of Bangladesh (Figure 1). Earthworm collection was made in paddy field, forest soil, municipal solid waste (MSW) dumped area, Colocasia field, poultry waste dumped area, vermiculture source, cowdung dumped area, fresh water mud, sewage water canals and garden soil.

\subsection{Collection and Identification of Earthworm Species}

A total 30 sampling sites were selected for collecting earthworm species and earthworm species were collected every week during the period of collection. Around 3 meter square areas were dug with the help of spade and scraper in each selected site. Visible earthworms were extracted from the soil by hand sorting procedure as well as with spade, shovel and basket. Collected live earthworms were stored in Basket and transfer to the fish breeding house under Department of Genetic Engineering and Biotechnology (GEB) at Shahjalal University of Science and Technology (SUST), Sylhet, Bangladesh. Collected earthworm species were identified based on morphological characteristics [4-6] and different species was counted for observing abundance of each species. Diversity of earthworm species was calculated based on Simpson Diversity Index [10] which is a measure that accounts the number of species present with the abundance of each species as well as proportion (percent) of each species.

Simpson diversity formula:

$\mathrm{D}=\frac{\left[\sum n(n-1)\right]}{[N(N-1)]}$, Whereas, $\mathrm{n}$ is the total number of organisms of each individual species and $\mathrm{N}$ is the total number of organisms of all species.

\subsection{Soil Sampling}

Soil samples $(0-15 \mathrm{~cm})$ were removed from the side of each earthworm pit after gently scraping away vertical sections of soil that may have been compacted by digging. Bulk density and soil moisture were determined using cylindrical cores inserted horizontally into a wall of each pit. All soil samples were placed in cold storage immediately and returned to the lab for subsequent analyses.

\subsection{Soil Analysis}

Collected soil samples were analyzed in the soil testing laboratory of the Soil Science Institute, Dakhin Surma, Sylhet, Bangladesh. Different parameters such as soil $\mathrm{pH}$, Potassium (K), Phosphorus (P) and Sulfur (S) were analyzed by standard protocols which are usually used in that laboratory.

\section{Results}

In this study, ecological diversity and abundance of earthworms were analyzed related to their habitats considering species identification and richness.

\subsection{Earthworm Diversity}

Earthworm species were collected and identified generally according to their morphological characteristics, habitats and size. Eight species such as Eisenia fetida, Amynthus aspergillum, Aporrectodea caliginosa, Aporrectodea longa, Lumbricus castaneus, Lumbricus terrestris, Lumbricus rubellus, Octolasion cyaneum were identified from different experimental sites.

\subsection{Earthworm Habitats}

Physical characters of the collected soils were analyzed and soil texture was found loamy, sandy, sandy loamy and clay loamy (Table 1). Different chemical parameters of the soil such as $\mathrm{pH}, \mathrm{K}, \mathrm{P}, \mathrm{S}$ concentration was tested which was related to the abundance of earthworm species (Table 1). Highest earthworm abundance was recorded in Kazitula (140) where the soil was clay loamy and the tested chemical conventions were good quality. On the other hand, the lowest abundance of earthworms was observed in Baluchar localities (27) and the soil texture of this soil was sandy loamy (Table 2). Though chemical parameters were found almost same in both localities, however, sulfur concentration was found higher in Baluchar sample. The different parameters of a good quality soil was standard an average pH-7.1-7.2, K 0.10-0.50 \%, P 0-28.56\%, S 7-45\% and most the soil samples was found between this standard which was related to the abundance of earthworm species in these habitats. Chemical characters of the loamy and clay loamy soil were adjacent to these parameters and consisted of high abundance of earthworm species rather than sandy soil which character did not assist these soils parameter and relatively low abundance of earthworm species was investigated. 
Table 1. Soil characteristics from different habitats and distribution of earthworms

\begin{tabular}{|c|c|c|c|c|c|c|c|c|c|c|c|c|c|c|c|}
\hline \multirow{2}{*}{$\mathrm{L}$} & \multirow{2}{*}{$\mathrm{S}$} & \multicolumn{5}{|c|}{ Soil characters } & \multirow[b]{2}{*}{ TNS } & \multicolumn{8}{|c|}{ Earthworm species } \\
\hline & & ST & $\mathrm{pH}$ & $\mathrm{K}$ & $\mathrm{P}$ & $\mathrm{S}$ & & $\mathrm{SP}_{1}$ & $\mathrm{SP}_{2}$ & $\mathrm{SP}_{3}$ & $\mathrm{SP}_{4}$ & $\mathrm{SP}_{5}$ & $\mathrm{SP}_{6}$ & $\mathrm{SP}_{7}$ & $\mathrm{SP}_{8}$ \\
\hline \multirow{3}{*}{$\mathrm{SC}(1)$} & 1 & Loamy & 6.4 & 0.19 & 8.7 & 66.4 & 32 & 7 & 4 & 8 & 4 & 3 & 3 & 1 & 0 \\
\hline & 2 & Loamy & 6.2 & 0.10 & 27.5 & 22.6 & 25 & 4 & 2 & 4 & 5 & 3 & 0 & 0 & 0 \\
\hline & 3 & Clay & 7.0 & 0.74 & 18.6 & 26.3 & 36 & 10 & 7 & 6 & 7 & 2 & 3 & 1 & 0 \\
\hline \multirow{3}{*}{ TB (2) } & 4 & Loamy & 6.7 & 0.19 & 6.4 & 45.6 & 29 & 9 & 5 & 7 & 6 & 2 & 0 & 0 & 0 \\
\hline & 5 & Loamy & 6.9 & 0.07 & 3.5 & 12.7 & 30 & 6 & 7 & 5 & 5 & 3 & 1 & 1 & 0 \\
\hline & 6 & SL & 6.9 & 0.04 & 1.2 & 13.4 & 24 & 8 & 4 & 5 & 4 & 2 & 1 & 0 & 0 \\
\hline \multirow{3}{*}{$\mathrm{D}(3)$} & 7 & Loamy & 6.1 & 0.06 & 0.78 & 18.0 & 29 & 8 & 6 & 7 & 6 & 2 & 0 & 0 & 0 \\
\hline & 8 & $\mathrm{CL}$ & 6.5 & 0.50 & 1.5 & 25.0 & 23 & 7 & 4 & 5 & 4 & 3 & 0 & 0 & 0 \\
\hline & 9 & Loamy & 6.3 & 0.10 & 1.0 & 36.8 & 22 & 4 & 3 & 2 & 3 & 2 & 2 & 0 & 1 \\
\hline \multirow{3}{*}{ MM (4) } & 10 & Loamy & 6.2 & 0.13 & 3.3 & 17.3 & 23 & 6 & 4 & 4 & 3 & 4 & 2 & 0 & 0 \\
\hline & 11 & Sandy & 6.8 & 0.19 & 2.7 & 16.0 & 22 & 6 & 6 & 5 & 3 & 2 & 0 & 0 & 0 \\
\hline & 12 & Loamy & 6.6 & 0.16 & 2.5 & 20.8 & 20 & 7 & 4 & 3 & 4 & 2 & 0 & 0 & 0 \\
\hline \multirow{3}{*}{ L (5) } & 13 & Loamy & 6.2 & 0.38 & 0.731 & 299.5 & 18 & 5 & 3 & 4 & 3 & 3 & 0 & 0 & 0 \\
\hline & 14 & Loamy & 6.0 & 0.04 & 0.661 & 122.5 & 16 & 4 & 5 & 2 & 2 & 3 & 0 & 0 & 0 \\
\hline & 15 & $\mathrm{CL}$ & 6.7 & 0.07 & 0.606 & 172.5 & 13 & 3 & 3 & 1 & 1 & 1 & 0 & 0 & 0 \\
\hline \multirow{3}{*}{ M (6) } & 16 & Sandy & 6.6 & 0.37 & 24 & 109.3 & 18 & 7 & 4 & 4 & 1 & 2 & 0 & 0 & 0 \\
\hline & 17 & SL & 6.7 & 0.33 & 24.7 & 103.3 & 14 & 5 & 2 & 4 & 2 & 1 & 0 & 0 & 0 \\
\hline & 18 & Loamy & 6.5 & 0.12 & 20 & 167.6 & 17 & 6 & 6 & 3 & 1 & 1 & 0 & 0 & 0 \\
\hline \multirow{3}{*}{ K (7) } & 19 & Loamy & 6.9 & 0.60 & 2.2 & 14.8 & 48 & 18 & 11 & 8 & 6 & 2 & 2 & 1 & 0 \\
\hline & 20 & $\mathrm{CL}$ & 7.2 & 0.15 & 3.3 & 10.5 & 46 & 13 & 9 & 7 & 7 & 3 & 4 & 1 & 2 \\
\hline & 21 & $\mathrm{CL}$ & 7.1 & 0.14 & 2.8 & 14.4 & 46 & 14 & 11 & 8 & 7 & 2 & 2 & 2 & 0 \\
\hline \multirow{3}{*}{ SE (8) } & 22 & $\mathrm{CL}$ & 6.8 & 0.29 & 1.9 & 36.1 & 40 & 11 & 9 & 8 & 6 & 3 & 2 & 0 & 1 \\
\hline & 23 & Loamy & 6.7 & 0.60 & 1.9 & 33.0 & 30 & 9 & 8 & 4 & 5 & 1 & 2 & 1 & 0 \\
\hline & 24 & CL & 6.9 & 0.11 & 2.1 & 12.1 & 37 & 14 & 6 & 6 & 7 & 2 & 2 & 0 & 0 \\
\hline \multirow{3}{*}{ B (9) } & 25 & SL & 7.0 & 0.80 & 18.4 & 56.8 & 9 & 3 & 2 & 1 & 1 & 2 & 0 & 0 & 0 \\
\hline & 26 & SL & 7.1 & 0.24 & 15.6 & 91.4 & 8 & 3 & 1 & 1 & 1 & 2 & 0 & 0 & 0 \\
\hline & 27 & SL & 7.1 & 0.29 & 20.1 & 131.4 & 8 & 2 & 2 & 3 & 1 & 0 & 0 & 0 & 0 \\
\hline \multirow{3}{*}{$\mathrm{T}(10)$} & 28 & Loamy & 6.8 & 0.18 & 1.9 & 37.7 & 12 & 5 & 2 & 1 & 4 & 0 & 0 & 0 & 0 \\
\hline & 29 & SL & 7.2 & 0.14 & 0.89 & 81.6 & 6 & 2 & 0 & 2 & 2 & 0 & 0 & 0 & 0 \\
\hline & 30 & Loamy & 6.7 & 0.15 & 0.95 & 160.3 & 9 & 3 & 1 & 3 & 2 & 0 & 0 & 0 & 0 \\
\hline
\end{tabular}

*L= Location, $\mathrm{S}=$ Sample, $\mathrm{ST}=$ Soil Type, TNS=Total Number of Species, $\mathrm{SC}=$ SUST Campus, TB=Tuker Bazar, $\mathrm{D}=$ Dhamalipara/Chowkidhekhi, MM=Modina Market, LT=Lakkatura, M= Malnichara, $\mathrm{K}=$ Kazitula, $\mathrm{SE}=$ Shahi Eidgah, $\mathrm{B}=$ Baluchar, $\mathrm{T}=$ Tilaghar, $\mathrm{SL}=\mathrm{Sandy}$ loamy, $\mathrm{CL}=\mathrm{Clay}$ loamy

\subsection{Distribution and Abundance of Earthworms}

In this study species diversity, ecological distributions and abundance of different earthworms were estimated on the basis of habitat of earthworm (Table 1,2). Though the abundance of different earthworms is related to the physical and chemical parameters, however, the diversity of the species were recorded highest in Kaztula and second highest with seven species were found in SUST campus, Tuker Bazar, Dhamalipara and Shahi Eidgha. Conversely the lowest species diversity was observed in Tilaghar and second lowest diversity with five species was found in Lakkatura, Manlichara and Baluchar. Finally, six species of earthworm diversity was recorded in Modina Market locality.

Three habitats from each locality were considered for observing the abundance of different earthworms in different ratios in different localities (Table 1). Two species such as $E$. fetida and A. aspergillum were found mostly in dominating status. Out of eight identified species Eisenia fetida, Amynthus aspergillum, Aporrectodea caliginosa, Aporrectodea longa was found all most all the localities while Lumbricus castaneus, Lumbricus terrestris, Lumbricus rubellus, Octolasion cyaneum was recorded very few and most of the sampling area they were completely absent (Table 1). 
Table 2. Simpson's diversity index and abundance of earthworm in ten localities of Sylhet region

\begin{tabular}{|c|c|c|c|c|}
\hline Localities & Habitat & Species & Diversity & Abundance \\
\hline SUST Campus (1) & 3 & 7 & 0.1735 & 93 \\
\hline Tuker Bazar (2) & 3 & 7 & 0.2012 & 83 \\
\hline Dhamalipara /Chowkidekhi (3) & 3 & 7 & 0.1875 & 74 \\
\hline Modina Market (4) & 3 & 6 & 0.1932 & 65 \\
\hline Lakkatura (5) & 3 & 5 & 0.1808 & 47 \\
\hline Malnichara (6) & 3 & 5 & 0.2431 & 49 \\
\hline Kazitula (7) & 3 & 8 & 0.1881 & 140 \\
\hline Shahi Eidgah (8) & 3 & 7 & 0.1903 & 107 \\
\hline Baluchar (9) & 3 & 5 & 0.19 & 25 \\
\hline Tilaghar (10) & 3 & 4 & 0.2086 & 27 \\
\hline
\end{tabular}

\subsection{Habitats and Species Interaction}

Observations of earthworm species abundance in the Sylhet region indicated that there were definite differences according to soil type both in total species numbers and in the relative numbers of species present (Table 2). The clay loamy appeared to carry higher earthworm species in total populations than the sandy loamy appeared to carry lower earthworm species (Table 1). Within and between the respective soil-type populations, species numbers were variable, but the actual numbers present on a soil type do not necessarily indicate the relative importance of each species. In all cases E. fetida was the dominant species, being more numerous on the clay loam than elsewhere. The abundance of $A$. aspergillum, A. caliginosa and A. longa were also observed in clay loamy. Species did not differ very much from $L$. castaneus and $L$. terrestris of the population on these two later soils and these two species were similar within populations, though much lower on the clay than on the other soils, and the total Lumbricus population number was highest on the loam and lowest on the clay (Table 2). There was a fair similarity between the two populations on the two open-textured soils, in both numbers and index values. Simpson's diversity index value was found lowest in SUST campus and highest in Malnichara localities while almost similar value was recorded in Dhamalipara, Lakkatura and Kazitula habitats (Table 2).

\section{Discussion}

Earthworm diversity and richness of the experimental sites was observed where habitat wise distribution of different species of earthworms in Sylhet Metropolitan area was presented. Out of eight identified species four species such as E. fetid, L. castaneus. A. longa and A. caliginosa were found in all localities. It was reported that earthworm activity is influenced by the soil parameters besides feed $[11,12]$ and the present research was agreed with that findings. It is known that lowest Simpson's diversity index value means highest diversity and it was found in SUST campus, Lakkatura, Dhamalipara and Kazitula and highest index value means lowest diversity while it was seen in Malnichara, Tuker bazaar and Tilagar respectively. The diversity index and species abundance of earthworms in Sylhet Metropolitan area was calculated where the factors such as the type of soil, climates, the available organic resources, land use pattern and disturbance that influence the diversity of earthworm communities [13]. However, Lee observed that commonly some amount of earthworm species were found in a given soil corroborates the present findings [14]. The highest number of earthworms was found near municipal waste area and lowest in the dry sandy area which is also agreed with a previous report [15]. The group distribution of earthworm population with maximum immature number of worms than mature worms at most of their active period of life was devised as well $[16,17]$. The high availability of feed and moisture content maintained in this man made environment appear to be the positive factors. Fragoso et al. have reported that the structural composition in earthworm communities varies depending on the type of agro-ecosystem [8] while similar observations were evident from the data of the present study. Soil type can also effect earthworm populations [14] and this study was also found the earthworm richness depends on soil characters.

\section{Conclusions}

A lot of research work has been done on earthworm biodiversity but unfortunately in Bangladesh a little emphasis has been given on research about earthworm. So, biodiversity of living earthworms in different soil conditions in Sylhet Metropolitan area of Bangladesh were studied and 8 different earthworm species were found from different study localities but their abundance was not found equally. This research is indicating that better understanding about habitat and living conditions of earthworms would provide suitable and enhanced production of vermicompost in different geographic conditions while vermicompost is a best fertilizer to increase soil structure, soil microbial communities and sustain long-term productivity of the soil. 
Due to morphological ambiguity of species identification rapid and cost effective molecular basis of species recognition should be taken.

\section{REFERENCES}

[1] J. W. Reynolds. Earthworms of the World. Global Biodiversity, 4:11-16, 1994.

[2] R. Harender and M. L. Bhardwaj. Earthworms: Role in soil biology, Chandighar, India, 2001.

[3] K. S. Rajiv, H. Sunil, A. Sunita, A. Ravi and C. Emilo. Vermiculture and waste management: study of action of earthworms Eisinia foetida, Eudrilus euginae and Perionyx excavatus on biodegradation of some community wastes in India and Australia, Earthworms environ. Sci., 22: 261-268, 2004.

[4] A. H. Ghosh. Earthworm Resources and Vermiculture. Zoological Survey of India, Calcutta, 1993.

[5] S. A. Ismail. Virmicology: Biology of Earthworm. Orient Longman, Hyderabad, India, 1997.

[6] J. J. Jimenez, E. A. Mamolarb and P. Lavelle. Biometric relationships in earthworms (Oligochaeta). European Journal of Soil Biology, 36: 45-50, 2000.

[7] M. C. Dash and V. C. Patra. Density, biomass and energy budget of trophical earthworm population from a grassland site in Orissa. India. Rev. Ecol. Biol. Sol. 14(3): 461-471, 1977.

[8] C. Fragoso, P. Lavelle, E. Blanchart, B. K. Senapati, J. J. Jimene, M. A. Martinez, T. Decaens and J. Tondoh. Earthworm communities of tropical agro-ecosystems: origin, structure and influence of management practices, In: Earthworm Management in Tropical Agro-ecosystem, CAB International, Wallingford, U.K. pp. 27-55, 1999.

[9] M. J. Sarwar, S. Sultana, P. Nasiruddin and S. Moniruzzaman. Earthworm diversity, distribution and abundance in Gibandia district of Bangladesh proceedings of national symposium environmental crisis and security in the millennium. pp 23-25, 2005.

[10] J. H. Zar. Biostatiscal Analysis, $4^{\text {th }} \mathrm{ed}^{\mathrm{n}}$, Prentice Hall International, U.S., 1999.

[11] D. K. Chaudry and K. Mitra. Fluctuation in earthworm populations in different soil conditions, Geobios 10: 55-59, 1983.

[12] C. A. Edwards and J. R. Lofty. (eds.). Biology of Earthworms, Chapman and Hall, London, U.K., 1972.

[13] C. A. Edwards and P. J. Bohlen. (eds.). Biology and Ecology of Earthworms, Chapman and Hall, London, U.K., 1996.

[14] K. E. Lee. Earthworms: Their Ecology and Relationships with Soil and Land Use, Vol. 5, Academic Press, New York, 1985.

[15] M. S. Jahan, S. Sultana, P. Nasiruddin and S. Monirruzzaman. Earthworm diversity, distribution and abundance in Gibandia districts of Bangladesh, In: A. B. Khan (ed.) Proceedings of National Symposium-Environmental Crisis and Security in the New Millennium, Anmol Publications Pvt. Ltd., India, pp. 23-35, 2005.

[16] A. C. Evans, W. J. Guild and L. Mc. Studies on the relationship between earthworms and soil fertility, IV, On the life cycles on some British Limbricidae, Annals of Applied Biology, 25: 471-484, 1948.

[17] P. Lavelle (1998). Large-scale effects of earthworm on soil organic matter and nutrient dynamics. Pages 103-122. In Edwards CA. ed. Earthworm Ecology Boca Raton (FL): St. Lucie Press. 